\title{
An Odyssey at the Interface - A Study in the Stream of Consciousness
}

\author{
Vuk Uskoković 1,2, (iD \\ 1 Advanced Materials and Nanobiotechnology Laboratory, TardigradeNano LLC, Irvine, CA 92604, United States; \\ vuk21@yahoo.com (V.U.); \\ 2 Department of Mechanical Engineering, San Diego State University, 5500 Campanile Dr., San Diego, CA 92182, United \\ States; vuskokovic@sdsu.edu (V.U.); \\ * Correspondence: vuk21@yahoo.com (V.U.);
}

Scopus Author ID 55900478100

Received: 18.07.2021; Revised: 5.09.2021; Accepted: 7.09.2021; Published: 17.10.2021

\begin{abstract}
Experimental science should be experimental in every aspect of it, from the life and career path of the experimenter to how its results and thoughts are being written up. In this paper, the author experiments with the stream of consciousness style of writing. To conform to this literary style, the text follows a natural train of thought that abounds with analogies and associations and deliberate typographic and syntactic omissions at times. Paying an homage to Joyce's Ulysses as the hallmark of the stream of consciousness writings, the author demonstrates empirically and through a bibliographic meta-analysis that a nanoparticle protected against biodegradation in lysosomal compartments of the cell, like Odysseus, takes significantly more time to return to its point of origin than to reach its intracellular destination. Thus, getting across the biological barrier and into the living system is less laborious and tardy than escaping from it. From here on, the corollaries of this finding relevant for the field of targeted drug delivery using nanoparticles are elaborated. This discussion is entwined with the storyline of the paper, which reflects Homer's epic poem about Odysseus and his long journey home. This experiment in scientific writing is motivated by the hope that rejuvenation of the literary style of technical papers in natural sciences might revitalize the rusty creativity and ill social relations underlying them. By experimenting with literary novelties and eventually adopting them as a common practice, science would be brought closer to the world of arts, at the interface of which it could rediscover its renaissance identity and flourish anew.
\end{abstract}

Keywords: Blood-brain barrier; cell biology; exocytosis; Homer; Odyssey; targeted drug delivery; Ulysses.

(C) 2021 by the authors. This article is an open-access article distributed under the terms and conditions of the Creative Commons Attribution (CC BY) license (https://creativecommons.org/licenses/by/4.0/).

\section{Introduction}

The reinvention of the scientific paper as a form of intellectual expression is one of the most critical goals posed before the scientists of this century [1, 2]. In this paper, the author flexes this form by experimenting with the stream of consciousness writing style. The first and the foremost introductory remark to be made at this point is that the originality and the analytical accuracy of the content of the empirical investigation reported here are not being compromised by even the slightest bit by this eagerness to innovate new ways of scientific expression.

Albeit presented in an unconventional form, the study elaborated here aimed to find out if a difference exists between the rate of endocytosis and the rate of exocytosis of a nanoparticle entering and exiting a cell, respectively. Both of these processes are prerequisites for an 
apposite therapeutic interaction between nanoparticles and cells to occur [3-6]. While endocytosis is a critical aspect of the cellular uptake of nanoparticles [7-9], exocytosis is equally critical for preserving the cells in viable states after the intracellular action of the given nanoparticles has been exerted [10-12], especially when these particles were not designed to degrade in the lysosome [13-16]. In what follows, the findings deduced from the elaboration of whether the rate of one of these two processes dominates over the other are presented by combining an experimental analysis and a bibliographic meta-analysis. This presentation is followed by a discussion of the relevance of these findings for the field of targeted drug delivery. This discussion is entwined with the storyline of the paper, which reflects Homer's epic poem about Odysseus and his long journey home.

\section{Materials and Methods}

Superparamagnetic iron oxide nanoparticles were precipitated from aqueous solutions containing $10 \mathrm{mM} \mathrm{FeCl}$ and $5 \mathrm{mM} \mathrm{FeCl}_{2}$ and 0.1 vol.\% Triton X-100 using a mixture of ammonia and $\mathrm{NaOH}$. The suspension of the magnetic nanoparticles obtained in the precipitation reaction continued to be stirred and aged for 1 hour at $80{ }^{\circ} \mathrm{C}$. Tetraethylorthosilicate was then added to the nanoparticle sols to deposit silica. Carbon-coated nanoparticles, a.k.a. earthicles, were created in a hydrothermal process (Parr), using 1:50 wt./vol. concentration of citric acid as the carbon coating precursor. To densify the resulting suspension and convert it to a ferrofluid, it was centrifuged in Amicon Ultra-4 centrifugal filter tubes (Ultracel 100-K, 100,000 $\mathrm{M}_{\mathrm{w}}$ ).

Madin-Darby Canine Kidney epithelial-like cells transfected with the human multidrug resistance gene (MDCK-MDR1, Netherlands Cancer Institute) were grown in Dulbecco's modified Eagle's medium (DMEM) at $37{ }^{\circ} \mathrm{C}$ and $5 \% \mathrm{CO}_{2}$. MDCK-MDR1 cells were seeded on coverslips fitted into standard 24-well cell culture plates and grown to confluency. When confluent, the cells were transfected transiently with LAMP1-YFP (Addgene plasmid \#1816) [17] using JetPrime transfection reagent (PolyPlus). The transfection lasted $24 \mathrm{~h}$, the period after which the cells were treated for $4 \mathrm{~h}$ with ferrofluids comprising $5 \mathrm{mg} / \mathrm{ml}$ of the composite nanoparticles. After $4 \mathrm{~h}$, the medium containing the nanoparticles was removed, and the cells were washed triply with phosphate-buffered saline (PBS). The cells were then flash-fixed in $4 \%$ paraformaldehyde for 30 seconds and stained for the nucleus with DAPI (4',6-diamidino2-phenylindole). LAMP1 primary antibody was used at the concentration of 1:100 relative to the commercial reagent (Abcam 24170), while the secondary anti-rabbit Alexa546 was used at the respective concentration of 1:400. After the fixation and the staining, the cells were rinsed with PBS and imaged under a Nikon T1-S/L100 confocal optical microscope. To visualize the nonfluorescent nanoparticles, the green background on the acquired images was subjected to RGB splitting during the image processing stage. The green channel was subsequently converted to a photographic negative, and RGB remerging (Jasc Paint Shop Pro 7.02) was carried out to allow for the visualization of the nanoparticles in green color.

\section{Results and Discussion}

On a vista beneath the marquee moon, I stood, the jigsaws trembling in my hand. The ball bounced out of range. Time is up, she said.

The oleander shrub sent a shiver, and I blinked. Then the eyes closed. Under the gutter caps, within the rusty pipes, the water flowed, lidded by silence, clearing the senses. The 
romance is on; the spiders climb the empty grooves, the thoughts zoom, flash, bliss, and then get lost. Like headlights on a highway at night. Kaboom, swish. Kaboom, swish. And gone.

Nanoparticle, aye, that desolate traveler through space. To guide it to an intracellular target is a dare that keeps thousands awake under these laurel wreath panoplies and shadows of classical orders. But what if it is all wrong? What if the way back, as in Homer's poem, is what is really challenging? What if the way home must be crossed to create targeted therapies that heal and leave no trace behind? The question drops into the mud, and the mud splashes into my eyes.

I am a lonely traveler, too, journeying into the night. Like the nanoparticle I travel, glory, glory, and nothing can stop me.

But the doubt flares up. An image crops up in flames. Four cells taking the nanoparticles in and spilling some out (Figure 1). Gaze at it, and visions walk up at ye. A door, a window, a chimney. They are not everywhere in the house. A peter a pan cannot hop in from anywhere. Likewise, endocytic and exocytic activities are not uniformly distributed across the cell membrane. Somewhere one is more pronounced, elsewhere another, yet elsewhere none [18]. With a whistle you go, the sunsets are calling. No more than $5 \%$ of the cell surface area is engaged in this transport of matter in and out [19]. A nanoparticle adhering onto one of these inactive areas may be stuck there for a long time, longer than the Amazonian rains and the Samarran arabesques, unless it can diffuse away and reattach and do so all over again, kissing and running, fondling and running, probing one patch of the surface after another in search of an unguarded gate overgrown by flowery shrubs, if not the gate guarded by the guardians with lei garlands in their open arms. Therefore, if one wants the particle to bind superbly to a cell via, say, antibodies or covalent ligand/receptor specificity, this may hinder the targeted delivery across the membrane and into the cell. It will go against the expectation and will crunch lush reveries into dry sand. Cling too hard and the heart of the clung to may remain a mystery.

Then, very often, as in life, the binding strength at the entrance point determines the fate at the exit. The hello is but a road paved to goodbye, the welcome hug a prelude to parting ways, a plush bear tucked under a blanket a gateway to the teenage daydreams of departure and autonomy. How the particle approaches, endocytosis may define how its exocytosis will proceed. Here is what the sun conjures. Take, for one, a ligand-binding onto a cell membrane receptor too strongly: it may be perceived by the cell as a perfect fit for it and its exocytosis, let alone the subsequent navigation to a more relevant target, may not proceed so easily, if at all [20]. Aren't these bandwagons looking nice rolling from this cliff into the ocean? For, all this fancy functionalization of nanoparticles with antibodies designed to bind specifically to transferrin or insulin receptors on the surface of the endothelial cells of the blood-brain barrier may lead to nothing; they may end up interacting with the cells of the blood-brain barrier so well that they never get near the brain cells, which they were directed to in the first place. How the doors are knocked on hides the key on how they will open; it determines what I will see when they open, too.

This door in my consciousness now opens for real, and streams are storming out, uninhibited, flooding the tidy coasts of logic with these visions of sci-fi urban landscapes harboring the rattling sounds of engines and a mental muss transforming to symmetry and order then numbness glossy alluring starts to reverberate across this starry space boat floating on an endless sea belling and trumpeting the beautiful being and verbosity are at odds as in movies as in movies heroic honest and stellar she says the Earth carries when no one cares but the vortices of inertia are here I exhale and slip into an abyss deelited dryad await the slump with 
stars twinkling eyes like champagne bubbles running grinding kicking hailing. And then back to the shell from this riot trail again.

There is an optimal size range for particles that undergo endocytosis to this swishing sound of sand falling through an hourglass, streaming toward eternity. This is why cells often wait for larger chunks of nanoparticles to adhere in greater amounts to the cell membrane before the uptake mechanism is launched and they are taken in altogether [21]. The $13 \mathrm{~nm}$ sized nanoparticles shown in Figure 1 are small enough to fall under this umbrella. The exit, therefore, is more of a solitary event, whereas the entrance is a congregational one, and this criterion can be used to differentiate between the two in Figure 1.

Is this why the closer I am to the way out of this burrow, the lonelier and more detached from the world I feel? I have you, but you are not the world I do not even know if I need except to awaken the lust of a tumultuous sea and fuel the city lights eyes in me, which get bedazzled to the point of blindness, craving a little tramp, hearty like a frayed orange, to make them see once again, lest the drop into dewy darkness be deeper with these social bonds shackling me and choking me and dragging me down, down, down onto comatose grounds where all things turn into one and stars begin to tinge down the rustic avenues and the tirades of town criers going,
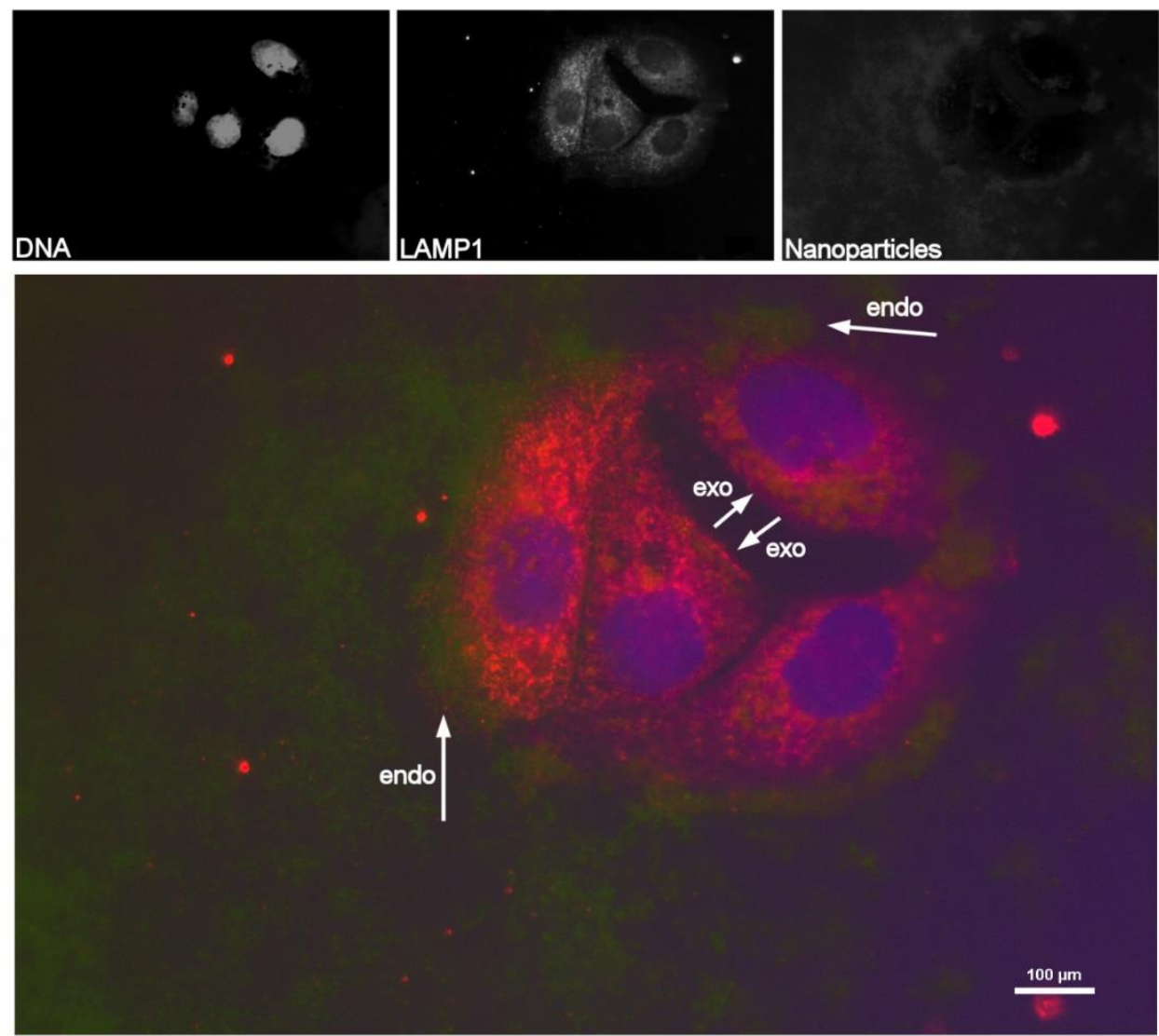

Figure 1. Immunohistochemistry of four epithelial, blood-brain barrier forming Madin-Darby canine kidney cells transfected with the human multidrug resistance gene (MDCK-MDR1) in interaction with magnetic nanoparticles. White arrows denote regions of the cells undergoing intense endocytosis but also regions where the intracellular nanoparticles are likely to be released to the basal end of the epithelial cells. Most of the lysosomes do not coincide with the nanoparticles, indicating that the cells are mostly engaged in the uptake of the nanoparticles rather than in their release. Nuclear DNA was stained with DAPI (blue), while lysosomalassociated membrane protein 1 (LAMP1) was stained by the transient transfection with LAMP1-YFP (red). Nanoparticles (green) were very narrowly dispersed, had $13 \mathrm{~nm}$ in size on average, and were composed of superparamagnetic iron oxide cores, silica shells and carbon crusts. Christened the earthicles, their synthesis and characterization are reported elsewhere [22-24]. 
Look at him, him, he trips, he trips, but the refuge is out of sight, and flakes and fog begin to smear over windows and mug gets high and visions hazy and windshields scratchy and the engine rattles and all stops in the middle of a highway, small hours lights-out, the twinkling of the stars only chiseling through the wheels of fate, and you and I, like twin stars in the night, there we go. The peace is found, but to the tick of the handless clock, atop the tower that ought to be saved, the tower assembled out of crumbly prison cells protecting skeletons and love letters smeared with blood and chocolate on their walls, bearing in the distance the bliss of a green plastic watering can on scales overlooking the daystar and the open sea and a pair of briery rosettes.

But this does not bring any solace. The sense of loss drifts through this muggy air, hand in hand with the ghosts of these vanished ruminations. The energy well has fallen into so deep, and the walls are so big. The way out, the way home, where are they?

Can a soliloquy, a monologue lead the way? No, I fear, for liberating can be only the path walked on with another on one's side. She must be here, she who loves the universe and every cocoon and grist in it. Without a chaperone to lead me by the hand, the way out will never be found. When the torch of I shines brighter than the torch of You, the road is barricaded, but from barracks on the other end emerges she, a careworn gamin with a withered daisy in her hair, a gold-leafed rag-dolled shadow with a dainty gag.

Lightly she treads, but can I look back? Will she slide back into the darkness? But if only straight I go, not far I shall reach from this cap of succor lying scrambled on the marble floor of this dim room lit by the crimson incubi and covered by the chard of mirrors that were to be walked through, not looked into, narcissistically, nor shattered into pieces, maddeningly. It all breaks into a scream wherefrom potato peelers drop their harvest onto the cracked floor of a cold northern cabin, the seeds sliding down to the Earth below and sprouting into trees that lift the house skyward, into the smoky seraphs' fluffy clouds and aerial views taken on by gulls and godwits whistle through the air.

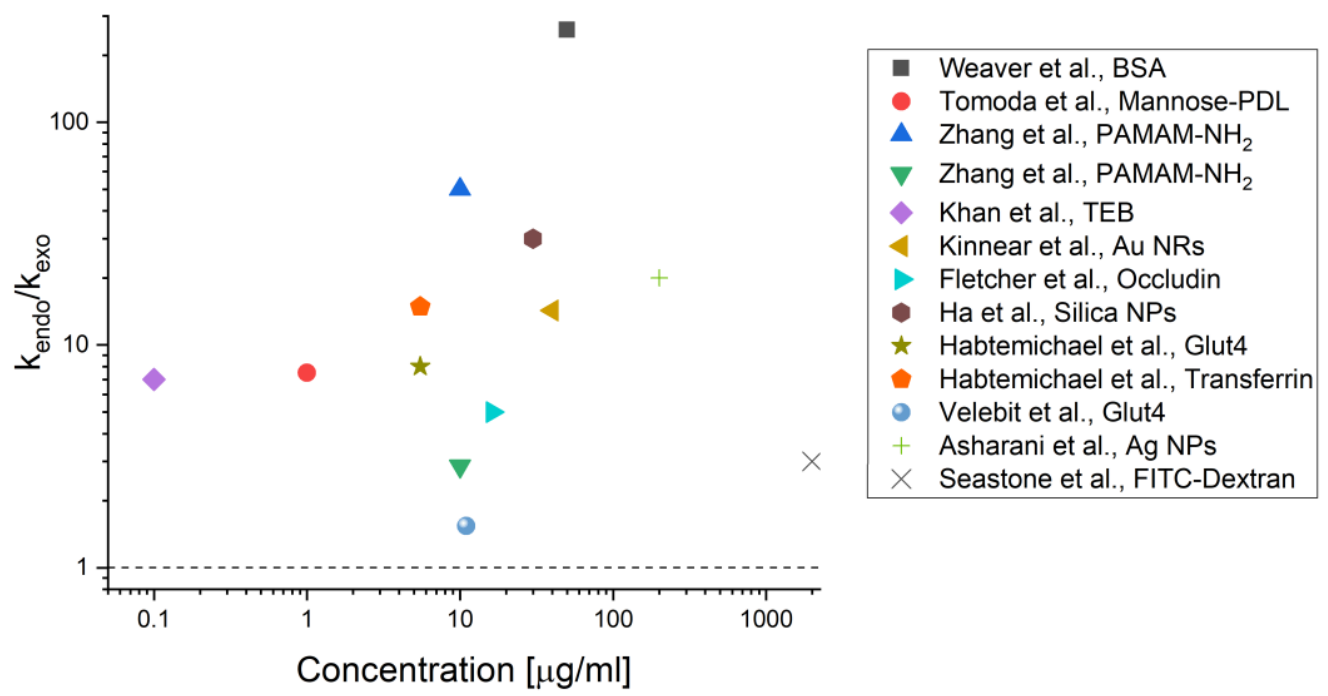

Figure 2. The ratio of the rate of endocytosis to the rate of exocytosis as a function of the concentration of the nanoparticle or macromolecule derived from various literature sources, including the following: Weaver et al. [25], Tomoda et al. [26], Zhang et al. [27], Khan et al. [28], Kinnear et al. [29], Fletcher et al. [30], Ha et al. [31], Velebit et al. [32], Habtemichael et al. [33], Asharani et al. [34], and Seastone et al. [35]. Abbreviations:

BSA - Bovine serum albumin, PDL - Poly-D-lysine, PAMAM - Polyamidoamine, TEB - Poly-

[triphenylalamine-4-vinyl-(p-methoxy-benzene)] nanoparticles, NRs - Gold nanorods, NPs - nanoparticles, FITC - Fluorescein isothiocyanate. All of the literature values exceed the ratio of 1 , meaning that endocytosis proceeds invariably faster than exocytosis. 
At the membrane, the boundary again, the river is calling, of Cocytus or Flowing Sands, its streams telling wordless stories, the prophets' heads bowing in shame. Does it take longer to get to the life of a cell, aye, or out of it? What if the difference between the rate of exocytosis and the rate of endocytosis gives away a clue? If one passage proceeds in a more complicated and laborious manner than the other, then it will be tardier too. A look deep into the artesian well of literature, with raggedy angels swinging boney legs from balconies and patting the searchers' stiff shoulders gently, shows this: the rate of endocytosis is invariably higher than the rate of exocytosis (Figure 2). In all the studies surveyed, the ratio between the two rates is vastly higher than 1. Indeed, to exit is harder than to enter. Cells in Figure 1, for one, internalize a sundry of particles, but a very fine number of them appears to have been sorted out for exocytosis. Alongside the studies reported in Figure 2, there are those that provide a more general estimate of endocytic activities in relation to their exocytic counterparts. They include the one [36] where the kinetic rate constants for the two processes were derived, whose ratio equaled 200 (10 vs. $0.05 \mathrm{~min}^{-1}$, respectively), and the one [37] where the total number of endocytic and exocytic events per cell was estimated at 19,720 $\mathrm{min}^{-1}$ and 2,686 $\mathrm{min}^{-1}$, respectively, wherefrom the ratio of 7.3 could be deduced. The same trend applies to other boundaries between the living systems and their outsides: oral, topical or corneal absorptions all proceed faster than the renal clearance, the transport into the brain from the blood prompter than the other way around, and so on.

To get from the blood to the brain, a nanoparticle must be transferred through transcytosis from one, apical end of the epithelial barrier cells, such as those captured in Figure 1, to the other, basal end, a process that requires coordinated endocytosis and exocytosis. Thanks to their silica and carbon coatings, nanoparticles from Figure 1 do not get degraded in the lysosome, and so they have the chance to be transferred to this other side. Here, speeding up exocytosis is crucial to enable a viable therapy that crosses the blood-brain barrier and prevents the traffic jam inside its cells, alongside causing potentially toxic effects. This exocytosis, in fact, can be argued to be more crucial for the transport across the blood-brain barrier than the endocytosis.

But the way out is long, necessitating the befriending of thousands of little things with funny flaps of bonds inside them, then retreating into corners before blasting through the rooms bursting with energy, then running out of the juices and swaddling inside secluded nests and rising from ashes and all over again, in a spiral where backward is often the only way forward and falling the only way of ascending. Falling like fading goddesses with bestrewed hairs and eyes wide open in horror, into the embrace of the Earth, via some aerial Via Appias, to touch and elate the dim and the dead, to enliven and resurrect and clasp and comfort and alleviate the pain.

The streams take over this little vessel out in the storm again, and deep within them, in their heart of hearts, wonder arises: why? Why all this transcription of chaos when orderliness seems dearer to the conveyance of scientific thought? How about this as a punch back: a concise and clear thought put in different forms will always resemble itself, but explicated on these free-flowing waves of consciousness, its forms are infinite, thus getting closer to Förster's ethical imperative: "Always act so as to increase the number of choices" [38]. This is how this writing with the spirit of freeness, devoid of inhibitions and regulations, crushing conventions into stardust, analogous and associative to the bone, becomes the route to the infinite, to acquainting the divinest depths of oneself, an experience godlier than that governed by strolling leisurely and aloofly down the evergreen corridors of logic and order. A truckload of times 
harder task it is too, with not only so many options raining on one, but also with erasures and destructions having to be used to build and construct, throwing the soul into the state of a bedazzling paradox. This sorting out amidst millions of choices, I know, leads the way deeper into the soul than roaming through the labyrinths of logic. This way deep into one is also, as I know by now too, the way out too.

The world is lonely and walls are still high, but they will be neither climbed over nor cut open, but slid through, in an act of Orphean magic. Here a toast is to be given to all the stutterers in the candlelight, the fearsome souls beneath the closed curtains of the stage, the trepidations underneath the torn sleeves, the myriads of odysseys and oracles emerging from mirages and prisms opening inside one, the echoes of the darkest hour before the dawn throughout the cosmic depths that know not of a pat or a pet, let alone a sound. To get the troublemaker aka Odysseus, across the border and into the life of a cell takes less effort than to have him leave it. Life is beautiful. It embraces all the things that arrive at its doorstep, foreign or familiar. But a star must withdraw to a dark and desolate row for its shine to bless another. To send a bird from a cage into the open sky is the most gracious and glorious of acts under this canopy of stars.

What these pigeon-toed musings from the edge of the pavement, under this marquee moon, hint at is that the way to the target, for a nanoparticle or anything else streaming through space 66,600 mph, is open. The way back home, as in Homer's epic, is what is challenging. It is, after all, the side effects that may be the main culprit behind the lack of substantial success of the traditional chemotherapies for treating diseases such as cancer. Therefore, maybe the question of targeting should be reversed in future research. Maybe studies should be run to solve the challenge of targeting the delivery of the systemically administered therapy out of the body, to a home that it had come from. This counterapproach in targeted drug delivery emerges here as a novel concept worth striving for.

Besides, endocytosis is a more stochastic, diffusion-related, concentration-gradient dependent process, as opposed to exocytosis, which requires lysosomes, peroxisomes, vacuoles, and other vesicles to transport the material to the membrane. There are far more checkpoints for a particle to go through to get out of the cell compared to the simpler process of getting into it. The cell is curious, wants to touch and twist and turn with each diffusive molecule and compartment of it this strange and foreign entity that the nanoparticle is. But it frustrates the lysosomes, and out the door, they send it. Besides, the vessel drowns when water gets into it, not when it surrounds it. And yet, the process of clearing, purifying from the inside out is far more complex than the process of absorbing and taking in from the outside.

And then the turn back and the reach of the hand, to save, judge not, causing a glitch, an error, a stumble and a fall down this ghostly hole and a spine-chilling slide into even greater darkness, slumping face forward and causing concussion wherefrom sun eclipses and topsyturvy orbits mingled with sailor salutes aboard the splitting ships shaken sunken all over America limbless sobbing mumbling flooded with dewdrops sailing seaward. And from it a gaze upwards and light is seen brighter than before, from this darkest ditch in the universe. Then, unknowingly to itself, like that bird that gazed at another, solemner bird [39] resting at the top of a fig tree above Charybdis, to which Odysseus clung for dear life after the shipwreck, it has become It and the exit sign has popped. Not a sign, but a sudden sense thereof. Accompanied by the light of a million stars and angelic choruses singing odes to the joy of You in voices unheard of, unimagined, and unthinkable. And then, just when it seems that the order has been restored, it all plunges into the sea, and blasts of joyous visions and thoughts 
erupt all around this holey aura of a weary and wretched traveler through a dream. YouandjoyandjoyandyouonderintheeisOrchidorholdUlyssesdragplungeAdrianscyllaRevolvdo wndownEndingNestOrbitfstarstamtorTheandALlmergeintoONEabc*\&outøaa $\square: \because \infty \ldots$ But no words are there any longer to describe these gusts of sound and vision. Tongues are tied, the heart is chockfull. No prophecy, only love amidst the ruins. Once and for all, this is goodbye to the conciseness and clarity of the streamlined syntax and good day to natural streams of consciousness, to the poetry of broken language, to the formless forms of infinite forms, to freedom of which angels have dreamt, to the white space around the confines of these letters, to being all, once and for all. With one such purified state of mind, discovered after a long journey through the forest of verbal complications, the end has been reached.

Before the nanoparticle from Figure 1, a new world opens. The cell membrane barrier has been crossed, and the brain, with its hundreds of billions of twinkly cells, a galaxy on its own, lies open before this miniature spaceship. But has it realized that, along the way, a greater barrier had been crossed, the blood-brain one, and that the way home will be even longer and unspeakably strenuous? Alas, there is no need to worry about that now. The road ahead is very long and this yet another quirky, misspelled Odyssey has just begun. For me, on the other hand, the road can end right here, for these words may be enough to start a revolution, peaceful and benevolent. I will watch from some distant hill and smile. My song will have reached the top of the cloud.

The sun is back.

The eyes open.

She watches me.

The tears and her clement smiles

are all that there is.

The sky breaks into a

yes yes yes.

We have made it through.

You and I.

Yay.

Breathe.

The crust sheds, The petals drop,

The flowers open, The mysteries are found, one more time.

The time is mine.

All of it in the world.

But I leave it

with you.

Outta bounce, outta frame

I go.

A step,

a quiet breath,

and then aught. 


\section{Conclusions}

It was demonstrated empirically and through a bibliographic meta-analysis that a nanoparticle protected against biodegradation in lysosomal compartments of the cell, like Odysseus, takes significantly more time to return to its extracellular point of origin than to reach its intracellular destination. For a nanoparticle, as the results of this study show, getting across the biological barrier and into the living system is less laborious and tardy than escaping from it.

These results are presented in a scientific paper of a completely novel form, namely, such that its central section was written by following the author's stream of consciousness. This experiment in scientific writing was motivated by the hope that rejuvenation of the literary style of technical papers in natural sciences might be a path to their rebirth across many different strata. By experimenting with literary novelties and eventually adopting them as a common practice, science would be brought closer to the world of arts, at the interface of which it could rediscover its renaissance identity and flourish anew.

\section{Funding}

This research received no external funding.

\section{Acknowledgments}

The author acknowledges the assistance of Victoria $\mathrm{M}$. Wu with the acquisition of immunochemistry data.

\section{Conflicts of Interest}

The author declares no conflict of interest.

\section{References}

1. Uskoković, V. Blowup of accidental images as a passageway to discovery: Insights into the interaction between hydroxyapatite nanoparticles and human mesenchymal stem cells. Applied Sciences 2014, 10, 8204, https://doi.org/10.3390/app10228204.

2. Uskoković, V.; Uskoković, E.; Uskoković, T.; Wu, V. And all the world a dream: Memory effects outlining the path to explaining the strange temperature-dependency of crystallization of water, a.k.a. the Mpemba effect. Substantia 2020, 4, 59-117, https://doi.org/10.13128/Substantia-89.

3. Erlichman, J.S.; Leiter, J.C. Complexity of the nano-bio interface and the tortuous path of metal oxides in biological systems. Antioxidants 2021, 10, 547, https://doi.org/10.3390/antiox10040547.

4. Torres-Vanegas, J.D.; Cruz, J.C.; Reyes, L.H. Delivery systems for nucleic acids and proteins: Barriers, cell capture pathways and nanocarriers. Pharmaceutics 2021, 13, 428, https://doi.org/10.3390/pharmaceutics13030428.

5. Zheng, Y.; Xing, L.; Chen, L.; Zhou, R.; Wu, J.; Zhu, X.; Li, L.; Xiang, Y.; Wu, R.; Zhang, L.; Huang, Y. Tailored elasticity combined with biomimetic surface promotes nanoparticle transcytosis to overcome $\begin{array}{lllll}\text { mucosal } & \text { epithelial } & \text { barrier. } & \text { Biomaterials } & \text { 2020, }\end{array}$ https://doi.org/10.1016/j.biomaterials.2020.120323.

6. Baidya, G.; Tiwary, R.; Mudassir, M.; Singh, N.; Saha, S.; Chosdol, K.; Sinha, S.; Chattopadhyay, P. Passive internalization and active extrusion determines PLGA-nanoparticle concentration in cancer cell lines. Nanomedicine 2020, 15, 2229-2239, https://doi.org/10.2217/nnm-2020-0229.

7. Ju, Y.; Guo, H.; Edman, M.; Hamm-Alvarez, S.F. Application of advances in endocytosis and membrane trafficking to drug delivery. Advanced Drug Delivery Reviews 2020, 157, 118-141, https://doi.org/10.1016/j.addr.2020.07.026. 
8. Iturrioz-Rodríguez, N.; Correa-Duarte, M.Á.; Valiente, R.; Fanarraga, M.L. Engineering sub-cellular targeting strategies to enhance safe cytosolic silica particle dissolution in cells. Pharmaceutics 2020, 12, 487, https://doi.org/10.3390/pharmaceutics12060487.

9. Istrate, C.M.; Holban, A.M.; Grumezescu, A.M.; Mogoantă, L.; Mogoşanu, G.D.; Savopol, T.; Moisescu, M.; Iordache, M.; Vasile, B.Ş.; Kovacs, E. Iron oxide nanoparticles modulate the interaction of different antibiotics with cellular membranes. Romanian Journal of Morphology and Embryology 2014, 55, 849-856.

10. Tancini, B.; Buratta, S.; Delo, F.; Sagini, K.; Chiaradia, E.; Pellegrino, R.M.; Emiliani, C.; Urbanelli, L. Lysosomal exocytosis: The extracellular role of an intracellular organelle. Membranes 2020, 10, 406, https://doi.org/10.3390/membranes10120406.

11. Liu, L.; Xu, K.; Zhang, B.; Ye, Y.; Zhang, Q.; Jiang, W. Cellular internalization and release of polystyrene microplastics and nanoplastics. Science of the Total Environment 2021, 779, 146523, https://doi.org/10.1016/j.scitotenv.2021.146523.

12. Kamalesh, K.; Scher, N.; Biton, T.; Schejter, E.D.; Shilo, B-Z.; Avinoam, O. Exocytosis by vesicle crumpling maintains apical membrane homeostasis during exocrine secretion. Developmental Cell 2021, 56, 16031616, https://doi.org/10.1016/j.devcel.2021.05.004.

13. Wu, V. M.; Uskoković, V. Fruit fly as a model organism for blood-brain barrier penetration and infectious disease in the nanomedical niche. Journal of Bionic Engineering 2020, 17, 553-569, https://doi.org/10.1007/s42235-020-0044-1.

14. Rau, J. V.; Fosca, M.; Fadeeva, I. V.; Kalay, S.; Culha, M.; Raucci, M. G.; Fasolino, I.; Ambrosio, L.; Antoniac, I. V.; Uskoković, V. Tricalcium phosphate bone cement supplemented with boron nitride nanotubes with enhanced biological properties. Materials Science and Engineering: C 2020, 114, 111044, https://doi.org/10.1016/j.msec.2020.111044.

15. Afifi, M.; Ahmed, M. K.; Fathi, A. M.; Uskoković, V. Physical, electrochemical and biological evaluations of spin-coated $\varepsilon$-polycaprolactone thin films containing alumina/graphene/carbonated hydroxyapatite/titania for tissue engineering applications. International Journal of Pharmaceutics 2020, 585, 119503, https://doi.org/10.1016/j.ijpharm.2020.119502

16. Mohd-Zahid, M. H.; Zulkifli, S. N.; Abdullah, C. A. C.; Lim, J.; Fakurazi, S.; Wong, K. K.; Zakaria, A. D.; Ismail, N.; Uskoković, V.; Mohamud, R.; Iskandar, Z.A. Gold nanoparticles conjugated with anti-CD133 monoclonal antibody and 5-fluorouracil chemotherapeutic agent as nanocarriers for cancer cell targeting. RSC Advances 2021, 11, 16131-16141, https://doi.org/10.1039/d1ra01093j.

17. Sherer, N. M.; Lehmann, M. J.; Jimenez-Soto, L. F.; Ingmundson, A.; Horner, S. M.; Cicchetti, G.; Allen, P. G.; Pypaert, M.; Cunningham, J. M.; Mothes, W. Visualization of retroviral replication in living cells reveals building into multivesicular bodies. Traffic 2003, 4, 785-801, https://doi.org/10.1034/j.16000854.2003.00135.x.

18. Carrillo, L.; Cucu, B.; Bandmann, V.; Homann, U.; Hertel, B.; Hillmer, S.; Thiel, G.; Bertl, A. Highresolution membrane capacitance measurements for studying endocytosis and exocytosis in yeast. Traffic 2015, 16, 760 -772, https://doi.org/10.1111/tra.12275.

19. Engstler, M.; Thilo, L.; Weise, F.; Grünfelder, C. G.; Schwarz, H.; Boshart, M.; Overath, P. Kinetics of endocytosis and recycling of the GPI-anchored variant surface glycoprotein in Trypanosoma brucei. Journal of Cell Science 2004, 117, 1105-1115, https://doi.org/10.1242/jcs.00938.

20. Vilella, A.; Rouzi, B.; Belletti, D.; Pederzoli, F.; Galliani, M.; Semeghini, V.; Forni, F.; Zoli, M.; Vandelli, M. A.; Tosi, G. Endocytosis of nanomedicines: The case of glycopeptide engineered PLGA nanoparticles. Pharmaceutics 2015, 7, 74-89, https://doi.org/10.3390/pharmaceutics7020074.

21. Shang, L.; Nienhaus, K.; Jiang, X.; Yang, L.; Landfester, L.; Mailander, V.; Simmet, T.; Nienhaus, G. U. Nanoparticles interactions with live cells: Quantitative fluorescence microscopy of nanoparticles size effects. Beilstein Journal of Nanotechnology 2014, 5, 2388-2397, https://doi.org/10.3762/bjnano.5.248.

22. Wu, V. M.; Huynh, E.; Tang, S.; Uskoković, V. Brain and bone cancer targeting by a ferrofluid composed of superparamagnetic iron-oxide/silica/carbon nanoparticles (earthicles). Acta Biomaterialia 2019, 88, 422447, https://doi.org/10.1016/j.actbio.2019.01.064.

23. Uskoković, V.; Huynh, E.; Tang, S.; Jovanović, S.; Wu, V. M. Colloids or powders: Which nanoparticle formulations do cells like more? Colloids and Surfaces B: Biointerfaces 2019, 181, 39-47, https://doi.org/10.1016/j.colsurfb.2019.05.019.

24. Uskoković, V.; Tang, S.; Wu, V. M. Targeted magnetic separation of biomolecules and cells using earthiclebased ferrofluids. Nanoscale 2019, 11, 11236-11253, https://doi.org/10.1039/C9NR01579E. 
25. Weaver, Jr., D. J.; Voss, Jr., E. W. Analysis of rates of receptor-mediated endocytosis and exocytosis of a fluorescent hapten-protein conjugate in a murine macrophage: Implications for antigen processing. Biology of the Cell 1998, 90, 169-181, https://doi.org/10.1016/s0248-4900(98)80338-99.

26. Tomoda, H.; Kishimoto, Y.; Lee, Y. C. Temperature effect of endocytosis and exocytosis by rabbit alveolar macrophages. Journal of Biological Chemistry 1989, 264, 15445-15450, https://doi.org/10.1016/S00219258(19)84849-44.

27. Zhang, J.; Liu, D.; Zhang, M.; Sun, Y.; Zhang, X.; Guan, G.; Zhao, X.; Qiao, M.; Chen, D.; Hu, H. The cellular uptake mechanism, intracellular transportation, and exocytosis of polyamidoamine dendrimers in multidrug-resistant breast cancer cells. International Journal of Nanomedicine 2016, 11, 3677-3690, https://doi.org/10.2147/IJN.S106418.

28. Khan, A. I.; Lu, Q.; Du, D.; Lin, Y.; Dutta, P. Quantification of kinetic rate constants for transcytosis of polymeric nanoparticles through blood-brain barrier. Biochimica et Biophysica Acta (BBA) - General Subjects 2018, 1862, 2779-2787, https://doi.org/10.1016/j.bbagen.2018.08.020.

29. Kinnear, C.; Rodriguez-Lorenzo, L.; Clift, M. J. D.; Goris, B.; Bals, S.; Rothen-Rutishauser, B.; Petri-Fink, A. Decoupling the shape parameter to assess gold nanorod uptake by mammalian cells. Nanoscale 2016, 8 , 16416-16426, https://doi.org/10.1039/C6NR03543D.

30. Fletcher, S. J.; Iqbal, M.; Jabbari, S.; Stekel, D.; Rappoport, J. Z. Analysis of occludin trafficking, demonstrating continuous endocytosis, degradation, recycling and biosynthetic secretory trafficking. PLOS One 2014, 9, e111176, https://doi.org/10.1371/journal.pone.0111176.

31. Ha, S. W.; Camalier, C. E.; Weitzmann, M. N.; Beck, Jr., G. R.; Lee, J. K. Long-term monitoring of the physicochemical properties of silica-based nanoparticles on the rate of endocytosis and exocytosis and consequences of cell division. Soft Materials 2013, 11, 195-203, https://doi.org/10.1080/1539445X.2012.617641.

32. Velebit, J.; Chowdhury, H. H.; Kreft, M.; Zorec, R. Rosiglitazone balances insulin-induced exo- and endocytosis in single 3T3-L1 adipocytes. Molecular and Cellular Endocrinology 2011, 333, 70-77, https://doi.org/10.1016/j.mce.2010.12.014.

33. Habtemichael, E. N.; Brewer, P. D.; Romenskaia, I.; Mastick, C. C. Kinetic evidence that Glut4 follows different endocytic pathways than the receptors for transferrin and alpha(2)-macroglobulin. Journal of Biological Chemistry 2011, 286, 10115-10125, https://doi.org/10.1074/jbc.M111.217935.

34. Asharani, P. V.; Hande, M. P.; Valiyaveettil, S. Anti-proliferative activity of silver nanoparticles. BMC Cell Biology 2009, 10, 65, https://doi.org/10.1186/1471-2121-10-65.

35. Seastone, D. J.; Harris, E.; Temesvari, L. A.; Bear, J. E.; Saxe, C. L.; Cardelli, J. The WASp-like protein Scar regulates micropinocytosis, phagocytosis and endosomal membrane flow in Dictyostelium. Journal of Cell Science 2001, 114, 2673-2683, https://doi.org/10.1242/jcs.114.14.2673.

36. Chavarria-Krauser, A.; Yeije, D. A model of plasma membrane flow and cytosis regulation in growing pollen tubes. Journal of Theoretical Biology 2011, 285, 10-24, https://doi.org/10.1016/j.jtbi.2011.06.008.

37. Ketelaar, T.; Galway, M. E.; Mulder, B. M.; Emons, A. M. C. Rates of exocytosis and endocytosis in Arabidopsis root hairs and pollen tubes. Journal of Microscopy 2008, 231, 265-273, https://doi.org/10.1111/j.1365-2818.2008.02031.x.

38. von Foerster, H. On constructing a reality. Understanding Understanding: Essays on Cybernetics and Cognition, H. von Foerster (Ed.), Springer New York 2010, 211-228.

39. Vivekananda, S. Jnana Yoga 1936. Ramakrishna Vivekananda Center, Calcutta. 